\title{
Iohexol plasma clearance in children: validation of multiple formulas and single-point sampling times
}

\author{
Camilla Tøndel $^{1,2}$ (1) $\cdot$ Cathrin Lytomt Salvador ${ }^{3,4} \cdot$ Karl Ove Hufthammer $^{5}$.

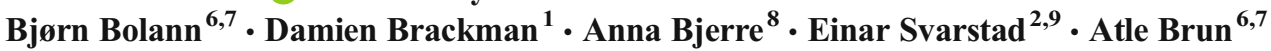

Received: 22 August 2017 / Revised: 31 October 2017 / Accepted: 1 November 2017 / Published online: 13 November 2017

(C) The Author(s) 2017. This article is an open access publication

\begin{abstract}
Background The non-ionic agent iohexol is increasingly used as the marker of choice for glomerular filtration rate (GFR) measurement. Estimates of GFR in children have low accuracy and limiting the number of blood-draws in this patient population is especially relevant. We have performed a study to evaluate different formulas for calculating measured GFR based on plasma iohexol clearance with blood sampling at only one time point (GFR1p) and to determine the optimal sampling time point.

Methods Ninety-six children with chronic kidney disease (CKD) stage 1-5 (median age 9.2 years; range 3 months to 17.5 years) were examined in a cross-sectional study using
\end{abstract}

Camilla Tøndel

camilla.tondel@helse-bergen.no

1 Department of Pediatrics, Haukeland University Hospital, 5021 Bergen, Norway

2 Department of Clinical Medicine, University of Bergen, Bergen, Norway

3 Department of Medical Biochemistry, Oslo University Hospital, Oslo, Norway

4 Institute of Clinical Medicine, Faculty of Medicine, University of Oslo, Oslo, Norway

5 Centre for Clinical Research, Haukeland University Hospital, Bergen, Norway

6 Laboratory for Clinical Biochemistry, Haukeland University Hospital, Bergen, Norway

7 Department of Clinical Science, University of Bergen, Bergen, Norway

8 Department of Pediatrics, Oslo University Hospital, Oslo, Norway

9 Department of Medicine, Haukeland University Hospital, Bergen, Norway iohexol clearance and blood sampling at seven time points within $5 \mathrm{~h}$ (GFR7p) as the reference method. Median GFR7p was 66 (range $6-153$ ) $\mathrm{mL} / \mathrm{min} / 1.73 \mathrm{~m}^{2}$. The performances of six different single time-point formulas (Fleming, Ham and Piepsz, Groth and Aasted, Stake, Jacobsson- and Jacobsson-modified) were validated against the reference. The two-point GFR (GFR2p) was calculated according to the Jødal and Brøchner-Mortensen formula.

Results The GFR1p calculated according to Fleming with sampling at $3 \mathrm{~h}$ (GFR $1 \mathrm{p}_{3 \mathrm{~h}}$-Fleming) had the best overall performance, with $82 \%$ of measures within $10 \%$ of the reference value (P10). In children with a GFR $\geq 30 \mathrm{~mL} / \mathrm{min} / 1.73 \mathrm{~m}^{2}$ $(n=78)$, the GFR $1 p_{3 \mathrm{~h}}$-Fleming had a P10 of $92.3 \%$, which is not significantly different $(p=0.29)$ from that of GFR2p $(\mathrm{P} 10=96.2 \%)$. Considerable differences within and between the different formulas were found for different CKD stages and different time points for blood sampling.

Conclusions For determination of mGFR in children with $\mathrm{CKD}$ and an assumed GFR of $\geq 30 \mathrm{~mL} / \mathrm{min} / 1.73 \mathrm{~m}^{2}$ we recommend GFR $1 \mathrm{p}_{3 \mathrm{~h}}$-Fleming as the preferred single-point method as an alternative to GFR2p. For children with a GFR $<30 \mathrm{~mL} / \mathrm{min} / 1.73 \mathrm{~m}^{2}$, we recommend the slope-GFR with at least two blood samples.

Clinical Trial Registration: ClinicalTrials.gov, Identifier NCT01092260, https:/clinicaltrials.gov/ct2/show/ NCT01092260?term=tondel\&rank=2

Keywords Glomerular filtration rate · Children · Chronic kidney disease $\cdot$ Renal function

\section{Introduction}

The low accuracy of formulas for estimating glomerular filtration rate (GFR) in children has long been a major challenge, 
with studies showing that less than $50 \%$ of the GFR levels estimated (eGFR) using formulas based on serum cystatin $\mathrm{C}$, creatinine and/or urea are within $\pm 10 \%$ of the gold standard GFR measurement [1]. In pediatric nephrology care, more accurate determinations of kidney function are therefore needed with a feasible measured GFR (mGFR) methodology based on the plasma clearance of an exogenous GFR marker. Since the 1980s, GFR has been increasingly measured using the non-ionic agent iohexol [2-7]. To avoid extended examinations with multiple blood samples for measuring GFR, many centers have chosen to use the one-pool slope-intercept technique with a minimum of two blood samples [8-11]. Numerous single-point GFR (GFR1p) methods have been developed, and especially in pediatric care, it is clearly beneficial to reduce the number of blood draws from two or three to a single sample, provided an adequate level of accuracy can be preserved [11-14]. However, current guidelines from the British Nuclear Medicine Society (BNMS) do not endorse the routine use of a GFR1p method and recommend a onepool slope-intercept technique requiring at least two samples [11]. The GFR1p methodology was introduced in adult patients by Fisher and colleagues in 1975 based on ${ }^{51} \mathrm{Cr}$-EDTA clearance [15], and an improved concept was described by Groth and colleagues in 1981 [16]. In 1983, Jacobsson published a formula for GFR1p which takes into account different distribution volumes and different sampling time points in adults based on ${ }^{99} \mathrm{TC}^{\mathrm{m}}$-DTPA clearance [12]. The Jacobsson formula has been widely used for GFR1p with different markers. Confusingly, modified versions of the Jacobsson formula have also been used but reported as being Jacobsson's original formula [14, 17-19]. Here we report results for Jacobsson's original adult single-point formula [12] and for the modified, non-iterative formula [14, 17], which does not include Jacobsson's correction for non-uniform distribution. Groth and Aasted published the first pediatric GFR1p formula in 1984 in which they used ${ }^{51} \mathrm{Cr}$-EDTA clearance with a sampling point at $2 \mathrm{~h}$ [20]. In 1991, Ham\&Piepsz published a new formula for GFR $1 p$ in children, also with sampling at $2 \mathrm{~h}$ and based on ${ }^{51} \mathrm{Cr}$-EDTA clearance. A modification of the Jacobsson formula for pediatric use was published the same year by Stake and colleagues; these authors recommended a sampling point at $3 \mathrm{~h}$ based on ${ }^{99} \mathrm{TC}^{\mathrm{m}}$-DTPA clearance $[3,21]$. In 2005, Fleming and colleagues described a new formula for GFR1p which they developed from a cohort of 100 children and 225 adults; this formula provided GFR values consistent with those obtained by the slope-intercept technique [22]. Although the Fleming formula first and foremost was suggested as a quality control method for the slope-intercept technique [22], a recent study [19] reports results arguing for the GFR1p-Fleming as a potential stand-alone formula for pediatric nephrology care.

The aims of our study were to: (1) assess the accuracy of the different formulas for GFR1p determination by comparison with the reference iohexol seven-point plasma clearance measurements (GFR7p) and (2) determine the optimal single time point for blood sampling for GFR1p within a feasible time frame (i.e. blood sampling not later than $5 \mathrm{~h}$ after injection).

\section{Patients and methods}

\section{Patients}

Ninety-six children with chronic kidney disease (CKD) were recruited in a cross-sectional study (ClinicalTrials.gov Identifier NCT01092260) which has evaluated the two-point methodology [23]: 54 children at Haukeland University Hospital, Bergen, Norway, and 42 children at Oslo University Hospital, Oslo, Norway. The median age of the included children ( 55 males, 41 females), was 9.2 years (range 3 months to 17.5 years), the median weight was 28.3 (range 6 . 6-84.6) $\mathrm{kg}$ and the median height was 134 (range 59-177) $\mathrm{cm}$. Median reference GFR based on seven blood sample time points (GFR7p) was 66 (range $6-153) \mathrm{mL} / \mathrm{min} / 1.73 \mathrm{~m}^{2}$. The individual GFR measurements were divided between the different GFR stages, namely, from 28, 27, 23, and 18 patients in CKD stage 1, 2, 3 and 4-5, respectively.

\section{Methods}

Iohexol was administered as Omnipaque ${ }^{\circledR} 300 \mathrm{mg} \mathrm{I} / \mathrm{mL}$ (647 mg iohexol/mL; GE Healthcare Technologies Norway AS, Oslo, Norway) in a dose adapted to body weight. Blood samples were drawn at 10,30 or $60,120,180,210,240$ and $300 \mathrm{~min}$ after injection. Additional details are provided in an earlier study published on the same cohort with a focus on two-point methodology [23].

\section{Calculations and statistics}

The GFR $7 p$ was calculated according to Sapirstein, as described by Schwartz et al. [3, 24] (Tables 1, 2). A twocompartment model was fitted using linear regression of the log concentration values. For three patients the twocompartment slope-intercept method could not be used due to negative values after the slow component of the curve was removed; for these three patients, we fitted the twocompartment model directly using non-linear least squares. GFR was normalized to $1.73 \mathrm{~m}^{2}$ body surface area (BSA) by the ratio 1.73/BSA, using the formula of Haycock et al. [25]. The GFR1p was calculated with six different formulas: the Fleming formula [22], the Ham and Piepsz formula (Ham\&Piepsz; [26], the Stake formula [13, 21], the Groth and Aasted formula (Groth\&Aasted; [20]), the Jacobsson formula [12] and a modification of Jacobsson's formula 
Table 1 Methodology of glomerular filtration rate calculations
GFR1p-Ham\&Piepz [26]

GFR1p-Groth\&Aasted [16]

GFR1p-Stake [13, 21]

GFR1p-Jacobsson [12]

GFR1p-Jacobsson-mod. [17]
Formula $^{\mathrm{b}}$

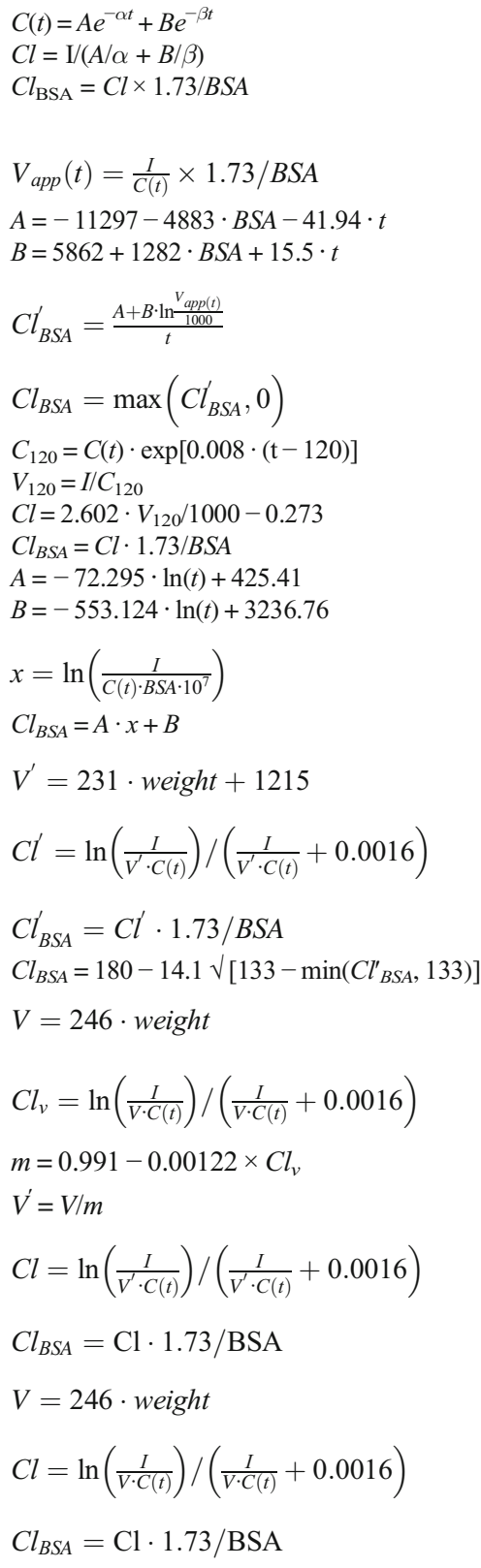

See Table 2 for additional formulas and an example

${ }^{a}$ GFR, Glomerular filtration rate; GFR7p, reference GFR based on seven blood sample time points; GFR1p, GFR value based on blood-draw at one time point

${ }^{\mathrm{b}} \mathrm{I}$, the dose of iohexol in $\mathrm{mg} ; C(t)$, the concentration in $\mathrm{mg} / \mathrm{mL}$ at $t$ min after injection; BSA, body surface area in $\mathrm{m}^{2}$, calculated according to Haycock [25]; $V$ and $V^{\prime}$, estimated volume of distribution; $\mathrm{Cl}$, unadjusted GFR; $\mathrm{Cl}_{\mathrm{BSA}}$, BSA-adjusted GFR estimate

${ }^{\mathrm{c}}$ See Patients and methods sections for additional information on calculation of the GFR7p value

(GFR1p-Jacobsson-mod.) [14, 17] which is based on performing only the first step in Jacobsson's three-step GFR calculation. Tables 1 and 2 show the formulas used in the calculation of the GFR values, along with numerical examples. One patient had an obviously incorrect value measured for the 3.5-h sample, and this value was therefore removed before the analyses; otherwise the data were complete, with no missing values. 
Table 2 Example data, with additional information on calculations

\begin{tabular}{|c|c|c|c|}
\hline Examples & Value & Units & Calculation/comment \\
\hline \multicolumn{4}{|l|}{ Product } \\
\hline Omnipaque & 300 & $\mathrm{mg} \mathrm{I} / \mathrm{ml}$ & \multirow{3}{*}{ Product density at room temperature. } \\
\hline Product density & 1.345 & $\mathrm{~g} / \mathrm{ml}$ & \\
\hline Iohexol density & 647 & $\mathrm{mg} / \mathrm{mL}$ & \\
\hline \multicolumn{4}{|l|}{ Injected dose } \\
\hline Omnipaque, weight & 2.8 & $\mathrm{~g}$ & \\
\hline Omnipaque, volume & 2.08 & $\mathrm{~mL}$ & $2.8 \mathrm{~g} / 1.345 \mathrm{~g} / \mathrm{mL}$ \\
\hline Iohexol, weight & 1346.9 & $\mathrm{mg}$ & $2.08 \mathrm{~mL} \times 647 \mathrm{mg} / \mathrm{mL}$ \\
\hline \multicolumn{4}{|l|}{ Example patient } \\
\hline Sample time & 180 & $\min$ & $3 \mathrm{~h} \times 60 \mathrm{~min} / \mathrm{h}$ \\
\hline Concentration & 0.100 & $\mathrm{mg} / \mathrm{mL}$ & $100 \mu \mathrm{g} / \mathrm{mL}$ \\
\hline Body weight & 13 & $\mathrm{~kg}$ & \\
\hline Body height & 90 & $\mathrm{~cm}$ & \\
\hline BSA & 0.574 & $\mathrm{~m}^{2}$ & 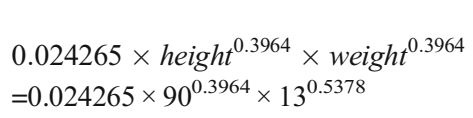 \\
\hline \multicolumn{4}{|l|}{ GFR1p values (BSA-adjusted) } \\
\hline GFR1p-Fleming & 72.9 & $\mathrm{~mL} / \mathrm{min} / 1.73 \mathrm{~m}^{2}$ & See Table 1 \\
\hline GFR1p-Ham\&Piepz & 64.6 & $\mathrm{~mL} / \mathrm{min} / 1.73 \mathrm{~m}^{2}$ & See Table 1 \\
\hline GFR1p-Groth\&Aasted & 61.8 & $\mathrm{~mL} / \mathrm{min} / 1.73 \mathrm{~m}^{2}$ & See Table 1 \\
\hline GFR1p-Stake & 76.5 & $\mathrm{~mL} / \mathrm{min} / 1.73 \mathrm{~m}^{2}$ & See Table 1 \\
\hline GFR1p-Jacobsson & 75.7 & $\mathrm{~mL} / \mathrm{min} / 1.73 \mathrm{~m}^{2}$ & See Table 1 \\
\hline GFR1p-Jacobsson-mod. & 74.9 & $\mathrm{~mL} / \mathrm{min} / 1.73 \mathrm{~m}^{2}$ & See Table 1 \\
\hline \multicolumn{4}{|l|}{ GFR7p calculations } \\
\hline \multicolumn{4}{|c|}{ Measured concentrations at all time points: } \\
\hline Time point & Time (min) & $C(t)(\mathrm{mg} / \mathrm{mL})$ & $C^{*}(t)(\mathrm{mg} / \mathrm{mL})$ \\
\hline 1 & 10 & 0.464 & 0.169 \\
\hline 2 & 30 & 0.343 & 0.082 \\
\hline 3 & 120 & 0.156 & - \\
\hline 4 & 180 & 0.100 & - \\
\hline 5 & 210 & 0.084 & - \\
\hline 6 & 240 & 0.072 & - \\
\hline 7 & 300 & 0.051 & - \\
\hline
\end{tabular}

Two-compartment model: $C(t)=A e^{-\alpha t}+B e^{-\beta t}=$ fast part + slow part

Regression of $\ln (C(t))$ on $t$ for the slow part (time point 3-7):

(Intercept) $\ln (B)=-1.16 \Rightarrow B=0.31$

(Slope) $-\beta=-0.0061 \Rightarrow \beta=0.0061$

$C^{*}(t)$ is the concentration after removing the slow part of the curve:

$C^{*}(t)=C(t)-B e^{-\beta t}=C(t)-0.31 e^{-0.0061 t}$

Regression of $\ln \left(C^{*}(t)\right)$ on $t$ (time point 1-2):

Intercept: $\ln (A)=-1.42 \Rightarrow A=0.24$

Slope: $-\alpha=-0.036 \Rightarrow \alpha=0.036$

AUC for fast part: $\frac{A}{\alpha}=\frac{A}{\alpha}=6.7$

AUC for slow part: $\frac{B}{\beta}=\frac{B}{\beta}=51.1$

Total $\mathrm{AUC}=51.1+6.7=57.8$

Unadjusted GFR**: $C l=\frac{I}{A U C}=\frac{I}{A U C}=23.3$

Glomerular filtration rate (GFR) adjusted for body surface area (BSA): $C l_{B S A}=G F R \cdot 1.73 / B S A=70.3$. Note that the final calculations are based on more decimals than are shown in the intermediate calculations 


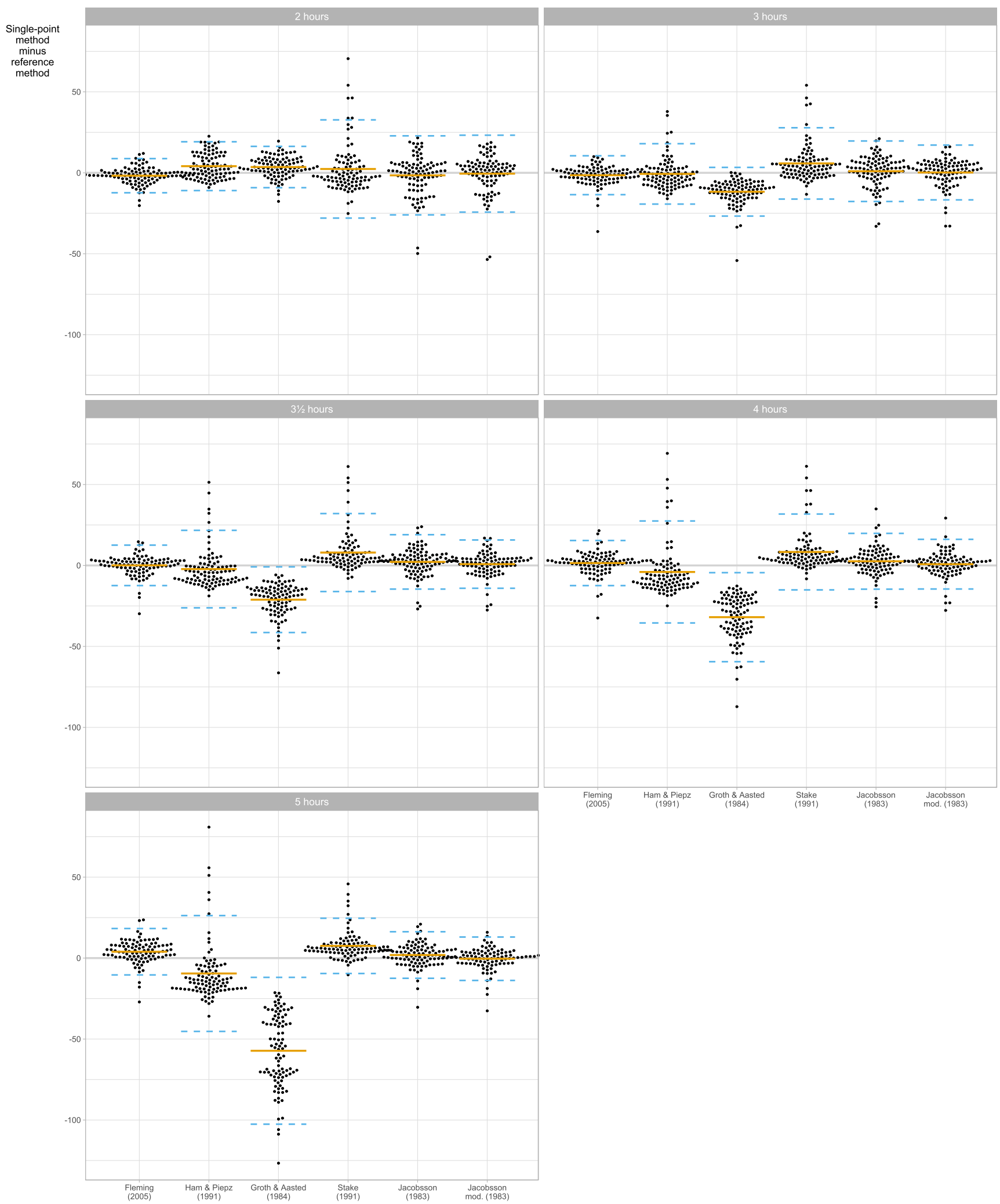

Fig. 1 Plot of estimation error versus the estimation method for glomerular filtration rate (GFR) calculated by six single-sample formulas $[12,13,17,20,22,26]$, stratified by sampling time point $(n=96$ children). The $y$-axis shows the difference between the single-point GFR and a reference GFR based on seven sampling time points. Each point corresponds to a combination of patient, estimation method and sample time.

The solid horizontal line is the bias, i.e. the mean difference between the single-point GFR estimate and the reference GFR. The dashed lines are limits of agreement, i.e. bias \pm two standard deviations of the differences. The figure can be used to compare different methods within each sampling time point 

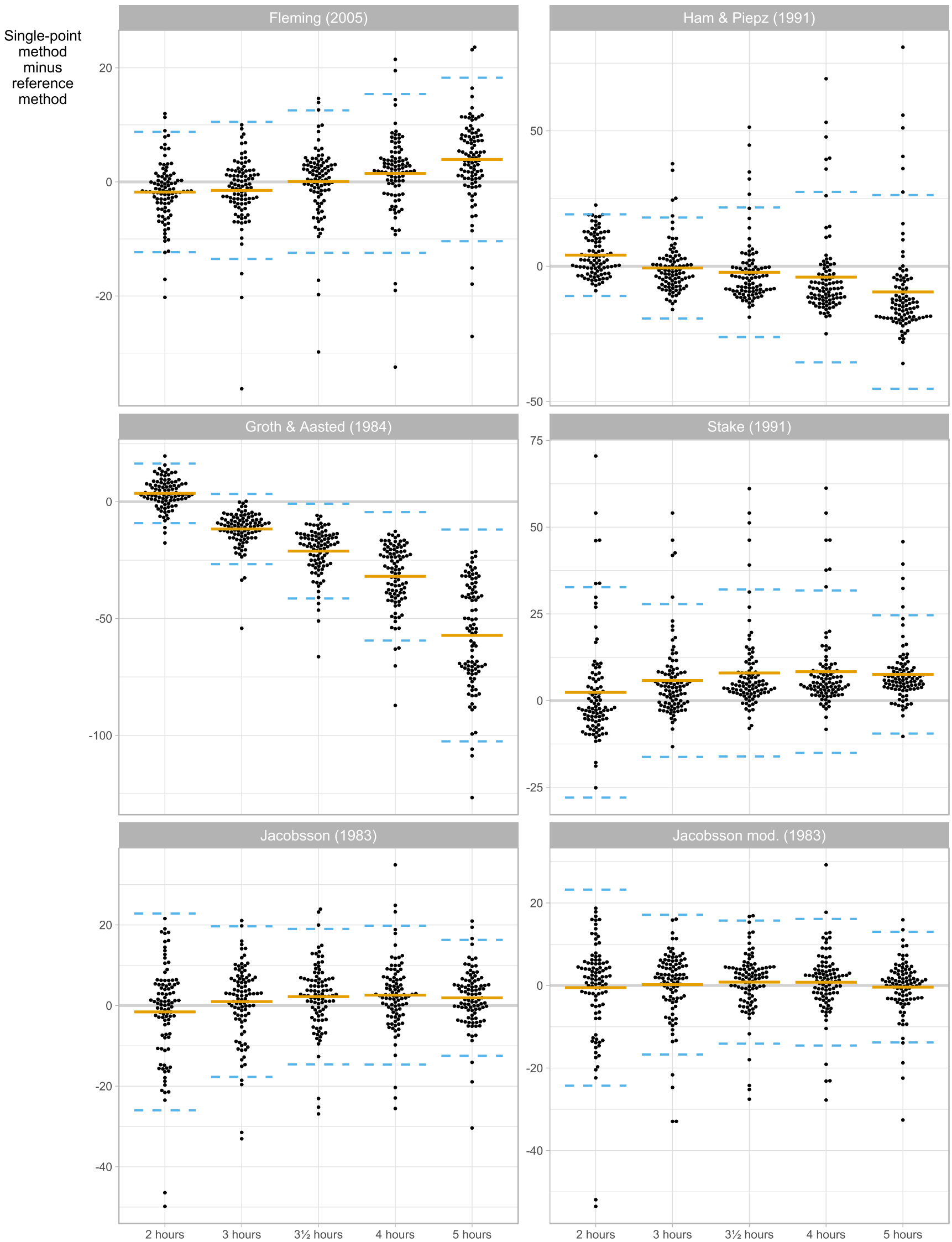
Fig. 2 Plot of estimation error versus time point for glomerular filtration rate (GFR) calculated at five time points, stratified by estimation method ( $n=96$ children). The $y$-axis shows the difference between the singlepoint GFR [12, 13, 17, 20, 22, 26] and a reference GFR based on seven sampling time points. Each point corresponds to a combination of patient, estimation method and sample time. The solid horizontal line is the bias, i.e. the mean difference between the single-point GFR and the reference GFR. The dashed lines are limits of agreement, i.e. bias \pm two standard deviations of the differences. For each estimation method, the figure can be used to compare the performance of the single-point GFR estimates at different sampling time-points
To compare the GFR1p methods and the reference method, we calculated the difference between the various GFR1p and the reference GFR for each patient, along with estimated bias (mean difference) and limits of agreement (bias \pm twice the standard deviation of the differences). The data are presented as difference plots comparing: (1) different methods within a single sampling time point (Fig. 1), (2) different sampling time points for each method (Fig. 2), and (3) the bias for different GFR values

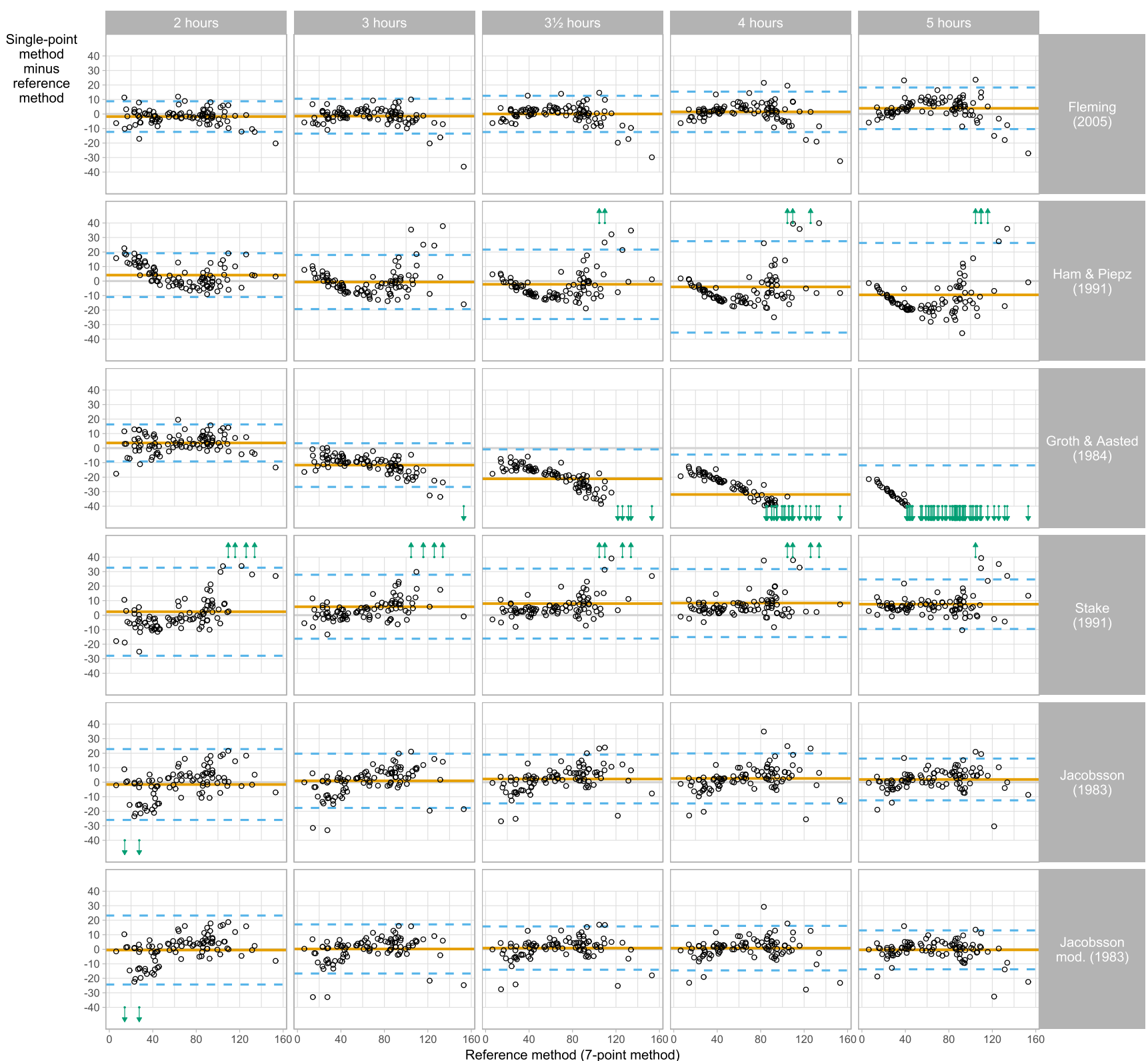

Fig. 3 Plot of estimation error versus reference glomerular filtration rate (GFR) for GFR calculated by six single-sample formulas [12, 13, 17, 20, $22,26]$ and at five sampling time points ( $n=96$ children). The $y$-axis shows the difference between the single-point GFR estimate and a reference GFR based on seven sampling time points. The $x$-axis shows the reference GFR. Each point corresponds to a combination of patient, determination method and sample time. The solid horizontal line is the bias, i.e. the mean difference between the single-point GFR and the reference GFR. The dashed lines are limits of agreement, i.e. bias \pm two standard deviations of the differences. Large determination errors, i.e. errors outside the displayed range, are indicated by arrows. The figure can be used to examine patterns in how the estimation errors of the different estimation methods vary with GFR for each method and sampling time 
for each method (Fig. 3). We also present the corresponding numerical estimates for the time points recommended in the original publications (Table 3 ) and for various subgroups (Table 5) according to age $(<10$ years and $\geq$ 10 years), BSA group $\left(<1.0 \mathrm{~m}^{2}\right.$ and $\left.<1.45 \mathrm{~m}^{2}\right)$ and stage of $\mathrm{CKD}\left(<30 \mathrm{~mL} / \mathrm{min} / 1.73 \mathrm{~m}^{2}, 30\right.$ to $<60 \mathrm{~mL} / \mathrm{min} / 1.73$ $\mathrm{m}^{2}, 60$ to $<90 \mathrm{~mL} / \mathrm{min} / 1.73 \mathrm{~m}^{2}, \geq 90 \mathrm{~mL} / \mathrm{min} / 1.73 \mathrm{~m}^{2}$ ).

To further quantify the performance of the GFR1pmethods, we calculated the number of GFR values that were within $5 \%, 10 \%, 15 \%$ or $20 \%$ of the reference method for each formula, labeled as P5, P10, P15 and P20, respectively, along with confidence intervals based on the recommended Wilson method [27] (Tables 3, 4, and 5; Fig. 4). Differences between methods and between time points for these 'P $x$ ' values $(x=5,10,15$ or 20) were evaluated using the McNemar test with mid$P$ correction.

For comparison, subanalyses for data on the best available two-point methodology (GFR2p) (Jødal and BrøchnerMortensen $[23,28,29])$ at 2 and $5 \mathrm{~h}$ (i.e. GFR2p-JBM) are also included in Tables 3, 4, and 5 .
We used $\mathrm{R}$ version 3.4.0 for Windows for all statistical analyses and figures [30]. Statistical significance is defined as $P$ values $\leq 0.05$, using two-sided tests, not adjusted for multiple comparisons.

\section{Results}

The performances of six different formulas for GFR1p determination $[12,13,20,22,26]$ compared to the reference method are shown in Tables 3, 4, and 5 and Figs. 1, 2, 3, and 4 . The results of different time points of blood sampling in Table 3 are limited to the recommended time points given in the respective original publications. The formula of Fleming with sampling at $3 \mathrm{~h}\left(\mathrm{GFR} 1 \mathrm{p}_{3 \mathrm{~h}^{-}}\right.$ Fleming) showed the best performance, with $82 \%$ of the GFR values falling within $10 \%$ of the reference method (P10). For the samplings at 2, 3, and 3.5 hours, the results with the Fleming formula were also significantly better than all the other tested formulas for P10 (Table 3). A comparison between the performances of all tested

Table 3 Effect of different formulas at their recommended time points

\begin{tabular}{|c|c|c|c|c|c|c|c|c|c|c|c|c|c|}
\hline \multirow[t]{3}{*}{ Formula } & \multicolumn{4}{|c|}{ Mean bias (GFR1p - GFR7p) } & \multicolumn{8}{|c|}{ Proportion of measures within $x \%$ of reference method $(95 \% \mathrm{CI})^{\mathrm{a}}$} & \multirow[t]{3}{*}{$P$ value $^{\mathrm{a}}$} \\
\hline & \multirow[t]{2}{*}{ Time (h) } & \multirow[t]{2}{*}{$r$} & \multirow[t]{2}{*}{ Bias } & \multirow{2}{*}{$\begin{array}{l}\text { Limits of } \\
\text { agreement }\end{array}$} & \multicolumn{2}{|l|}{ P5 } & \multicolumn{2}{|l|}{$\mathrm{P} 10$} & \multicolumn{2}{|l|}{$\mathrm{P} 15$} & \multicolumn{2}{|l|}{$\mathrm{P} 20$} & \\
\hline & & & & & $\begin{array}{l}\% \text { of } \\
\text { measures }\end{array}$ & $95 \% \mathrm{CI}$ & $\begin{array}{l}\% \text { of } \\
\text { measures }\end{array}$ & $95 \% \mathrm{CI}$ & $\begin{array}{l}\% \text { of } \\
\text { measures }\end{array}$ & $95 \% \mathrm{CI}$ & $\begin{array}{l}\% \text { of } \\
\text { measures }\end{array}$ & $95 \% \mathrm{CI}$ & \\
\hline \multirow[t]{4}{*}{ GFR1p-Fleming } & 2 & 0.99 & -1.8 & -12.3 to 8.8 & 54 & $44-64$ & 79 & $70-86$ & 86 & $78-92$ & 90 & $82-94$ & 0.42 \\
\hline & 3 & 0.98 & -1.5 & -13.5 to 10.5 & 56 & $46-66$ & 82 & $73-89$ & 89 & $81-93$ & 91 & $83-95$ & N/A \\
\hline & 3.5 & 0.98 & 0.1 & -12.4 to 12.5 & 44 & $35-54$ & 81 & $72-88$ & 87 & $79-93$ & 89 & $82-94$ & 0.51 \\
\hline & 4 & 0.98 & 1.5 & -12.4 to 15.4 & 41 & $31-51$ & 75 & $65-83$ & 90 & $82-94$ & 92 & $84-96$ & 0.10 \\
\hline $\begin{array}{l}\text { GFR1 } \\
\text { p-Ham\&Piepz }\end{array}$ & 2 & 0.98 & 4.1 & -11.0 to 19.2 & 42 & $32-52$ & 64 & $54-72$ & 73 & $63-81$ & 76 & $67-83$ & $<0.001$ \\
\hline $\begin{array}{l}\text { GFR1 } \\
\text { p-Groth\&Aasted }\end{array}$ & 2 & 0.98 & 3.6 & -9.2 to 16.3 & 35 & $27-45$ & 65 & $55-73$ & 75 & $65-83$ & 81 & $72-88$ & $<0.001$ \\
\hline GFR1p-Stake & 3 & 0.97 & 5.8 & -16.2 to 27.8 & 33 & $25-3$ & 66 & $56-74$ & 78 & $69-85$ & 82 & 73-89) & 0.002 \\
\hline \multirow[t]{5}{*}{ GFR1p-Jacobsson } & 2 & 0.97 & -1.6 & -26.0 to 22.8 & 32 & $24-42$ & 58 & $48-68$ & 69 & $59-77$ & 78 & $69-85$ & $<.001$ \\
\hline & 3 & 0.98 & 1.0 & -17.7 to 19.7 & 34 & $26-44$ & 58 & $48-68$ & 74 & $64-82$ & 81 & $72-88$ & $<.001$ \\
\hline & 3.5 & 0.98 & 2.2 & -14.6 to 19.0 & 27 & $19-37$ & 64 & $54-73$ & 75 & $65-82$ & 82 & $73-89$ & $<.001$ \\
\hline & 4 & 0.98 & 2.6 & -14.6 to 19.8 & 32 & $24-42$ & 65 & $55-73$ & 76 & $67-83$ & 88 & $79-93$ & $<.001$ \\
\hline & 5 & 0.98 & 1.9 & -12.5 to 16.3 & 43 & $33-53$ & 72 & $62-80$ & 85 & $77-91$ & 91 & $83-95$ & 0.04 \\
\hline \multirow{5}{*}{$\begin{array}{l}\text { GFR1 } \\
\text { p-Jacobsson-mod. }\end{array}$} & 2 & 0.97 & -0.5 & -24.3 to 23.2 & 33 & $25-43$ & 61 & $51-71$ & 70 & $60-78$ & 78 & $69-85$ & $<0.001$ \\
\hline & 3 & 0.98 & 0.2 & -16.7 to 17.1 & 35 & $27-45$ & 69 & $59-77$ & 75 & $65-83$ & 84 & $76-90$ & 0.003 \\
\hline & 3.5 & 0.98 & 0.8 & -14.1 to 15.7 & 41 & $32-51$ & 65 & $55-74$ & 80 & $71-87$ & 88 & $80-93$ & $<0.001$ \\
\hline & 4 & 0.98 & 0.8 & -14.5 to 16.1 & 42 & $32-52$ & 71 & $61-79$ & 85 & $77-91$ & 91 & $83-95$ & 0.02 \\
\hline & 5 & 0.98 & -0.4 & -13.8 to 13.0 & 50 & $40-60$ & 74 & $64-82$ & 90 & $82-94$ & 94 & $87-97$ & 0.08 \\
\hline GFR2p-JBM & 2 and 5 & 0.99 & -1.7 & -9.4 to 6.1 & 73 & $63-81$ & 97 & $97-99$ & 100 & $96-100$ & 100 & $96-100$ & $<0.001$ \\
\hline
\end{tabular}

Evaluation of optimal time for blood sampling was investigated using five different sampling time points after iohexol injection, namely 2, 3, 3.5, 4 and $5 \mathrm{~h}$. glomerular filtration rate (GFR) $\left(\mathrm{mL} / \mathrm{min} / 1.73 \mathrm{~m}^{2}\right)$ was estimated by one-point methods at time points recommended in the original publications ( $n=96$ for all time points except for $3.5 \mathrm{~h}$, where $n=95)$ and by the reference method (GFR7p). Mean bias, $95 \%$ limits of agreement and correlation $(r)$ with reference method are shown calculated. For comparison the two-point method of Jødal Brøchner Mortensen (GFR2p-JBM) was added

N/A, Not applicable

${ }^{\text {a }}$ Estimated accuracy is shown as P5, P10, P15 and P20, namely, the percentage of patients within $\pm 5,10,15$ and $20 \%$ of the reference method, respectively, along with $95 \%$ confidence intervals (CI)

${ }^{\mathrm{b}}$ Comparison with Fleming P10 at $3 \mathrm{~h}$ 
GFR1p formulas and slope-intercept methodology revealed that the GFR2p-JBM methodology was significantly better than all GFR1p formulas in the entire cohort of children with CKD 1-5 (Tables 3, 4).

With respect to the effect of sampling time on the performance, the Fleming formula gave results for sampling at 2, 3.5 and $4 \mathrm{~h}$ (i.e. time frame recommended by Fleming) which were not significantly different from the results at $3 \mathrm{~h}$ (Table 3; Figs. 2, 4). However, when blood was drawn at $5 \mathrm{~h}$ (i.e. outside the time frame recommended by Fleming), this formula showed a significantly lower performance, with a P10 of 55\% $(P<0.01)$ (Table 4; Figs. 2, 4). When sampling at $4 \mathrm{~h}$, the Fleming and Jacobsson-mod. formulas performed significantly better (P10 was 75 and $71 \%$, respectively) than the formulas of Ham \& Piepsz, Groth \& Aasted and Stake (Figs. 1, 4). For blood sampling at $5 \mathrm{~h}$, the two Jacobsson formulas had the best performance, with a P10 of 74 and $72 \%$, respectively, which was significantly better $(P<0.01)$ than the performance of all other tested formulas at $5 \mathrm{~h}$ (Figs. 1, 4; Tables 3, 4).

All GFR1p formulas studied showed large bias when blood was drawn outside the time frames originally described for the respective formulas (Fig. 1). Nevertheless, the formulas of Fleming and Jacobsson gave relatively good GFR1p determinations for the entire 2- to 5-h range (Figs. 2, 3). The GFR1p formulas also showed non-constant bias (and, to a lesser degree, variance) over the GFR range (Fig. 3), especially outside their recommended time frames. However, the Fleming and Jacobsson formulas at their bestperforming time points ( 3 and $5 \mathrm{~h}$, respectively) had an approximately constant bias and variance as a function of GFR (Fig. 3).

Subgroup analysis revealed that in children with CKD $1-3$, GFR $1 p_{3 \mathrm{~h}}$-Fleming scored very well, with a P10 of $92 \%$, which was significantly better than those of all other GFR1p formulas investigated, and not significantly different from the P10 of GFR2p-JBM, which was $96 \%$ $(P=0.29)$ (Table 4$)$. In those patients with a GFR < $30 \mathrm{~mL} / \mathrm{min} / 1.73 \mathrm{~m}^{2}$, much lower performances were found for all GFR1p formulas. In this subgroup, the highest P10 was $67 \%$ when the GFR1p-Fleming formula was used with blood sampling at $5 \mathrm{~h}\left(\mathrm{GFR} 1 \mathrm{p}_{5 \mathrm{~h}^{-}}\right.$ Fleming). However, the performance of GFR $1 p_{5 h^{-}}$ Fleming was not significantly better than that of the GFR $1 \mathrm{p}_{5 \mathrm{~h}}$-Jacobsson which had a P10 of $44 \%$ $(P=0.23)$. In contrast, the GFR2p-JBM scored $100 \%$ for P10 $(P<0.0001)$ in the patients with GFR < $30 \mathrm{~mL} / \mathrm{min} / 1.73 \mathrm{~m}^{2}$ (Tables 4, 5).

Age and BSA did not seem to influence the scores of GFR1p-Fleming, whereas GFR1p-Ham\&Piepsz, GFR1pGroth\&Aasted and GFR1p-Jacobsson all had better scores in the smaller children (Table 5).

\section{Discussion}

The results of our iohexol plasma clearance study of a cohort of 96 children with CKD 1-5 shows that GFR1p measurements reached acceptable precision in patients with CKD 13. The best formula for single-point measured GFR in children was the GFR1p-Fleming, which showed a significantly better performance than the GFR1p-Ham\&Piepsz, GFR1pGroth\&Aasted and GFR1p-Stake formulas [13, 20-22, 26] at all tested time points (Table 3; Fig. 1). GFR1p-Fleming was also significantly better than GFR1p-Jacobsson [12] when blood samplings were done after 2, 3 and 3.5 hours, whereas no significant difference was found between these formulas at $4 \mathrm{~h}$ (Table 4; Fig. 4). For blood sampling at $5 \mathrm{~h}$, GFR1p-Jacobsson was significantly better than all other single-point formulas (Table 4; Fig. 1). Comparison with the two-point methodology showed that GFR2p-JBM, with a P10 of $97 \%$, was significantly better $(P<0.001)$ than all singlepoint methods investigated in this study when all CKD stages were included in the analysis. However, an interesting finding was evident from the subgroup analysis, which showed no significant difference between the best single-point method, GFR $1 p_{3 h}$-Fleming, and GFR2p-JBM in children with CKD 1-3 (Tables 4, 5). The scores for all single-point formulas were low in children with CKD 4-5, with the best P10 of $67 \%$ compared to $100 \%$ with GFR2p-JBM $(P<0.001)$ (Tables 4,5 ). McMeekin and colleagues recently compared the GFR $1 p_{3 h}$-Fleming with a multi-point reference method in a combined cohort of children and adults, with a total of 411 tests (247 pediatric and 164 adult tests) [19]. These authors found that $92.7 \%$ of measures [95\% confidence interval (CI) 90-95\%] were within $20 \%$ of the reference. This is in accordance with the results from our cohort showing a P20 of 91\% (95\% CI 83-95\%). Our results also support the discrepancy between formulas reported by McMeekin and colleagues who found lower P20 for GFR1 $\mathrm{p}_{2 \mathrm{~h}}-\mathrm{Ham} \&$ Piepsz, GFR $1 \mathrm{p}_{2 \mathrm{~h}^{-}}$ Groth\&Aasted, GFR $1 \mathrm{p}_{3 \mathrm{~h}}$-Stake and GFR $1 \mathrm{p}_{4 \mathrm{~h}}$-Jacobsson compared to GFR1p 3h $_{\mathrm{h}}$-Fleming in their cohort [19].

Our study clearly demonstrates the importance of using the optimal blood sampling time points adapted to each formula. This is especially evident in the methods described by Ham\&Piepsz and Groth\&Aasted [11, 26], where the performance scores of all time points outside the recommended are low (Figs. 2, 3; Table 4). Furthermore, variable performance across GFR levels has to be taken into account since both these formulas scored fairly well in children with CKD 1-2, whereas the scores were unacceptably low in children with CKD 3-5 (Table 4). As the GFR1p-Ham\&Piepsz formula has been a recommended single-point method in guidelines [11] and was developed from a high number $(n=657)$ of GFR measurements [26], a higher general score should be expected. Interestingly, in our study, the P10 of GFR1p-Ham\&Piepsz was very high in the group of children with CKD 2, with a 


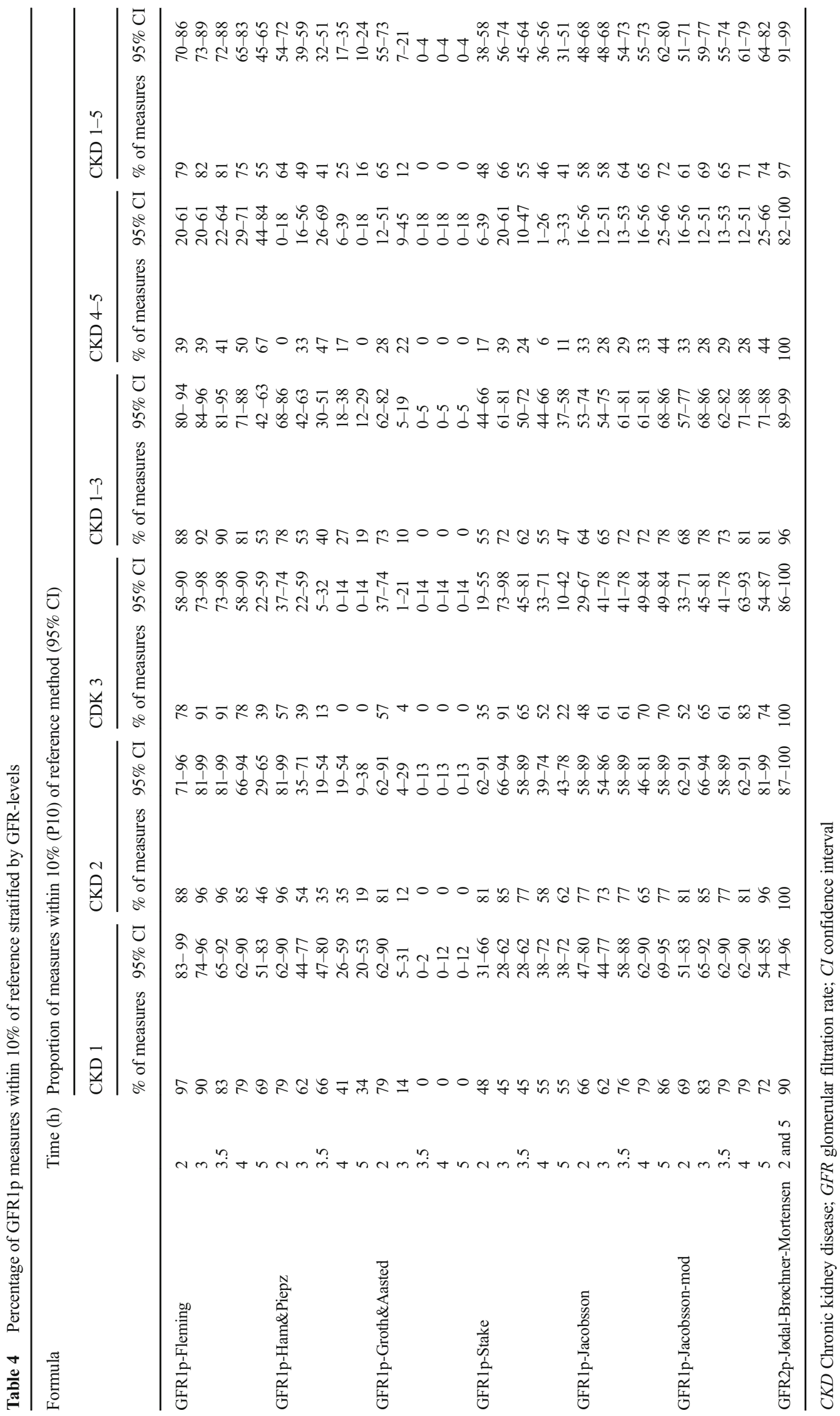



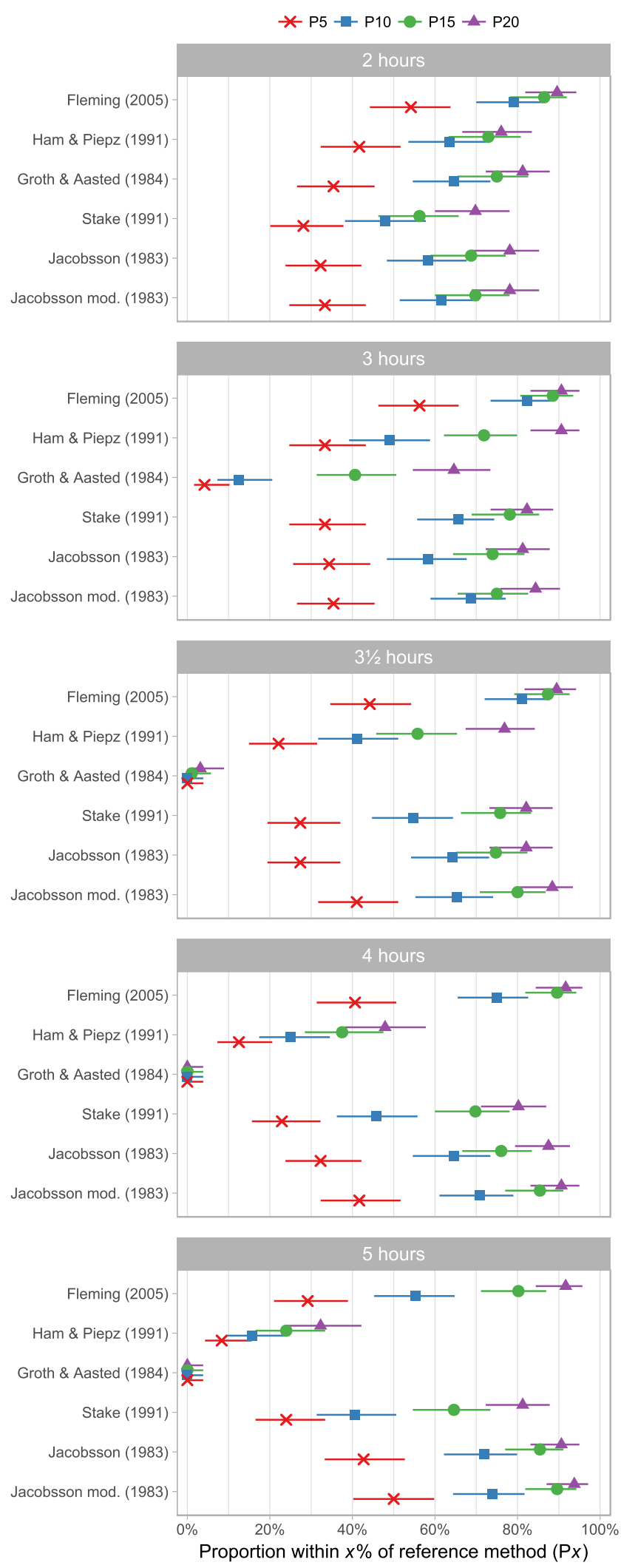

P 10 of $96 \%$, but only $57 \%$ in those with CKD 3 , and no patient was within $10 \%$ of the reference with a GFR of $<$
Fig. 4 Percentage plot showing the determination accuracy of six singlesample determination methods $[12,13,17,20,22,26]$ at five sampling time points ( $n=96$ patients/children). Each symbol, labeled P $x$ (P5, P10, P15 and P20), shows the calculated proportion of single-sample glomerular filtration rate (GFR) within $x \%$ of the reference method. The horizontal lines show the corresponding $95 \%$ confidence intervals

$30 \mathrm{~mL} / \mathrm{min} / 1.73 \mathrm{~m}^{2}$ (Table 4). A plausible explanation could be that the reference method used in the Ham \& Piepsz study was not a multipoint-method, and the development of the formula was based on GFR measurements mainly in the normal range [26].

The Groth \& Aasted formula was developed in a cohort with a broader distribution of GFR [16], which could explain why the single-point scores with this formula were more evenly distributed across the different CKD groups in our study (Table 4). The cohort of Groth \& Aasted was, however, considerably smaller, and their five-point reference GFR had the last time point set early $(2 \mathrm{~h})$ [20], which probably explains the low scores in general for GFR1p-Groth\&Aasted. The fairly good scores for GFR1p-Stake in children with CKD $2-3$ at $3 \mathrm{~h}$ in contrast to the low scores for those with CKD 1 and CKD 4-5 (Fig. 2; Table 4) are probably due to the fact that the Stake-formula was developed in a cohort of 100 children mainly with CKD 2-3 and with a two-point ${ }_{3 \mathrm{~h}, 4 \mathrm{~h}}$ iohexolGFR as reference method [13].

Both the Fleming and the Jacobsson formulas have distribution volume and time-point adaption included in the respective formulas. This gives a lower vulnerability in terms of time-point variability for blood sampling, as long as the true sampling time is used in the formula. The GFR $1 \mathrm{p}_{3 \mathrm{~h}}$-Fleming scored significantly better $(P<0.05)$ than all other formulas on their recommended time points, except for GFR $1 \mathrm{p}_{5 \mathrm{~h}}$-Jacobsson-mod. $(P=0.08)$ (Table 3 ) in the cohort as a whole, and it was not significantly different from GFR2p-JBM in the subgroups CKD 1, CKD 2 and CKD 3. The subgroup analysis also showed that age and body size did not significantly influence the scores of GFR1p-Fleming. Importantly, when a child is expected to have CKD 4-5, our study shows that a single-point methodology with blood sampling up to $5 \mathrm{~h}$ is not recommended and that at least two blood samples should be collected (Table 5). Calculation of the eGFR [1], despite its limitations, can be helpful in making the decision to take more than one blood-sample or not, i.e. with $30 \mathrm{ml} / \mathrm{min} / 1.73 \mathrm{~m}^{2}$ as the cutoff value.

Iohexol has been increasingly used as a marker for GFR measurements in recent decades. It is a nonradioactive substance, safe, inexpensive, has low inter-laboratory variation and is stable and easy to use [4, 31, 32]. Although the GFR1p-Fleming formula was originally developed using a radioactive marker in adults and children [21], 
Table 5 Subgroup analysis

\begin{tabular}{|c|c|c|c|c|c|c|c|c|c|c|c|}
\hline \multirow[t]{2}{*}{ Patient group } & \multirow[t]{2}{*}{ Formula } & \multirow[t]{2}{*}{ Time (h) } & \multirow[t]{2}{*}{$n$} & \multirow[t]{2}{*}{$r$} & \multicolumn{2}{|c|}{$\begin{array}{l}\text { Mean bias } \\
(\text { GFR } 1 p-\text { GFR } 7 p)\end{array}$} & \multicolumn{4}{|c|}{$\begin{array}{l}\text { Percentage of measures within } x \% \\
\text { of reference method }(\mathrm{P} x)^{\mathrm{a}}\end{array}$} & \multirow[t]{2}{*}{$P$ value $^{\mathrm{b}}$} \\
\hline & & & & & Bias & Limits of agreement & P5 & P10 & $\mathrm{P} 15$ & $\mathrm{P} 20$ & \\
\hline \multirow[t]{7}{*}{ Age $<10$ years } & GFR1p-Fleming & 3 & 52 & 0.99 & -0.5 & -9.7 to 8.8 & 65 & 83 & 88 & 92 & $\mathrm{~N} / \mathrm{A}$ \\
\hline & GFR1p-Ham\&Piepz & 2 & 52 & 0.97 & 2.3 & -13.3 to 17.8 & 48 & 73 & 83 & 87 & 0.15 \\
\hline & GFR1p-Groth\&Aasted & 2 & 52 & 0.99 & 2.0 & -10.7 to 14.7 & 40 & 69 & 81 & 87 & 0.02 \\
\hline & GFR1p-Stake & 3 & 52 & 0.97 & 7.3 & -14.1 to 28.6 & 29 & 62 & 75 & 79 & 0.008 \\
\hline & GFR1p-Jacobsson & 5 & 52 & 0.98 & 2.0 & -11.1 to 15.1 & 52 & 79 & 90 & 92 & 0.55 \\
\hline & GFR1p-Jacobsson-mod. & 5 & 52 & 0.98 & 0.1 & -12.8 to 13.0 & 58 & 81 & 90 & 94 & 0.77 \\
\hline & GFR2p-JBM & 2 and 5 & 52 & 0.99 & -2.0 & -10.2 to 6.3 & 60 & 96 & 100 & 100 & 0.02 \\
\hline \multirow[t]{7}{*}{ Age $\geq 10$ years } & GFR1p-Fleming & 3 & 44 & 0.98 & -2.7 & -17.1 to 11.6 & 45 & 82 & 89 & 89 & N/A \\
\hline & GFR1p-Ham\&Piepz & 2 & 44 & 0.99 & 6.3 & -7.1 to 19.6 & 34 & 52 & 61 & 64 & 0.001 \\
\hline & GFR1p-Groth\&Aasted & 2 & 44 & 0.99 & 5.4 & -6.6 to 17.3 & 30 & 59 & 68 & 75 & 0.02 \\
\hline & GFR1p-Stake & 3 & 44 & 0.98 & 4.1 & -18.5 to 26.6 & 39 & 70 & 82 & 86 & 0.11 \\
\hline & GFR1p-Jacobsson & 5 & 44 & 0.98 & 1.8 & -14.1 to 17.7 & 32 & 64 & 80 & 89 & 0.04 \\
\hline & GFR1p-Jacobsson-mod. & 5 & 44 & 0.98 & -1.0 & -15.0 to 13.0 & 41 & 66 & 89 & 93 & 0.02 \\
\hline & GFR2p-JBM & 2 and 5 & 44 & 1.0 & -1.4 & -0.5 to 5.8 & 89 & 98 & 100 & 100 & 0.02 \\
\hline \multirow[t]{7}{*}{$\mathrm{BSA}<1.0 \mathrm{~m}^{2}$} & GFR1p-Fleming & 3 & 47 & 0.99 & 0.0 & -9.5 to 9.6 & 68 & 81 & 87 & 91 & N/A \\
\hline & GFR1p-Ham\&Piepz & 2 & 47 & 0.97 & 2.9 & -13.0 to 18.7 & 43 & 68 & 79 & 83 & 0.09 \\
\hline & GFR1p-Groth and Aasted & 2 & 47 & 0.99 & 2.1 & -11.3 to 15.5 & 45 & 64 & 79 & 85 & 0.01 \\
\hline & GFR1p-Stake & 3 & 47 & 0.98 & 7.6 & -12.1 to 27.3 & 23 & 57 & 72 & 77 & 0.008 \\
\hline & GFR1p-Jacobsson & 5 & 47 & 0.97 & 1.5 & -12.4 to 15.4 & 57 & 83 & 89 & 89 & 0.73 \\
\hline & GFR1p-Jacobsson-mod. & 5 & 47 & 0.98 & -0.2 & -13.6 to 13.3 & 60 & 83 & 91 & 94 & 0.75 \\
\hline & GFR2p-JBM & 2 and 5 & 47 & 0.99 & -1.9 & -10.1 to 6.3 & 60 & 96 & 100 & 100 & 0.02 \\
\hline \multirow[t]{7}{*}{$\mathrm{BSA}<1.45 \mathrm{~m}^{2}$} & GFR1p-Fleming & 3 & 77 & 0.99 & -0.4 & -9.6 to 8.9 & 60 & 84 & 90 & 92 & N/A \\
\hline & GFR1p-Ham\&Piepz & 2 & 77 & 0.97 & 3.4 & -11.7 to 18.4 & 42 & 65 & 77 & 81 & $<0.001$ \\
\hline & GFR1p-Groth\&Aasted & 2 & 77 & 0.98 & 3.1 & -9.5 to 15.6 & 39 & 68 & 78 & 86 & 0.001 \\
\hline & GFR1p-Stake & 3 & 77 & 0.97 & 7.2 & -15.6 to 30.0 & 30 & 64 & 75 & 81 & $<0.001$ \\
\hline & GFR1p-Jacobsson & 5 & 77 & 0.98 & 2.6 & -10.8 to 15.9 & 48 & 75 & 87 & 92 & 0.10 \\
\hline & GFR1p-Jacobsson-mod. & 5 & 77 & 0.98 & 0.6 & -11.5 to 12.6 & 55 & 77 & 91 & 96 & 0.17 \\
\hline & GFR2p-JBM & 2 and 5 & 77 & 0.99 & -1.7 & -9.7 to 6.3 & 69 & 96 & 100 & 100 & 0.01 \\
\hline \multirow[t]{7}{*}{ CKD stage 1} & GFR1p-Fleming & 3 & 29 & 0.83 & -4.1 & -21.9 to 13.8 & 59 & 90 & 93 & 97 & N/A \\
\hline & GFR1p-Ham\&Piepz & 2 & 29 & 0.93 & 2.6 & -12.6 to 17.8 & 59 & 79 & 97 & 100 & 0.34 \\
\hline & GFR1p-Groth\&Aasted & 2 & 29 & 0.91 & 4.3 & -8.7 to 17.3 & 48 & 79 & 97 & 100 & 0.34 \\
\hline & GFR1p-Stake & 3 & 29 & 0.82 & 14.9 & -15.4 to 45.1 & 21 & 45 & 66 & 72 & 0.001 \\
\hline & GFR1p-Jacobsson & 5 & 29 & 0.82 & 2.6 & -17.0 to 22.3 & 45 & 86 & 86 & 93 & 0.69 \\
\hline & GFR1p-Jacobsson-mod. & 5 & 29 & 0.81 & -2.9 & -21.5 to 15.7 & 55 & 72 & 97 & 97 & 0.03 \\
\hline & GFR2p-JBM & 2 and 5 & 29 & 0.92 & -1.7 & -15.3 to 9.1 & 59 & 90 & 100 & 100 & 0.81 \\
\hline \multirow[t]{7}{*}{ CKD stage 2} & GFR1p-Fleming & 3 & 26 & 0.93 & 0.4 & -6.8 to 7.7 & 73 & 96 & 100 & 100 & N/A \\
\hline & GFR1p-Ham\&Piepz & 2 & 26 & 0.91 & -0.7 & -9.5 to 8.0 & 62 & 96 & 96 & 96 & 0.75 \\
\hline & GFR1p-Groth\&Aasted & 2 & 26 & 0.91 & 5.5 & -3.5 to 14.5 & 42 & 81 & 92 & 96 & 0.06 \\
\hline & GFR1p-Stake & 3 & 26 & 0.89 & 3.9 & -7.1 to 15.0 & 38 & 85 & 92 & 96 & 0.13 \\
\hline & GFR1p-Jacobsson & 5 & 26 & 0.93 & 4.6 & -4.3 to 13.5 & 42 & 77 & 96 & 100 & 0.03 \\
\hline & GFR1p-Jacobsson-mod. & 5 & 26 & 0.94 & 2.1 & -5.5 to 9.7 & 58 & 96 & 96 & 100 & 0.75 \\
\hline & GFR2p-JBM & 2 and 5 & 26 & 0.96 & -2.0 & -7.6 to 3.7 & 69 & 100 & 100 & 100 & 0.50 \\
\hline \multirow[t]{4}{*}{ CKD stage 3} & GFR1p-Fleming & 3 & 23 & 0.97 & 0.0 & -4.8 to 4.9 & 61 & 91 & 100 & 100 & N/A \\
\hline & GFR1p-Ham\&Piepz & 2 & 23 & 0.77 & 3.7 & -6.2 to 13.6 & 30 & 57 & 70 & 78 & 0.01 \\
\hline & GFR1p-Groth\&Aasted & 2 & 23 & 0.78 & 1.9 & -9.5 to 13.3 & 35 & 57 & 65 & 74 & 0.004 \\
\hline & GFR1p-Stake & 3 & 23 & 0.96 & 0.6 & -5.0 to 6.2 & 48 & 91 & 100 & 100 & 1.00 \\
\hline
\end{tabular}


Table 5 (continued)

\begin{tabular}{|c|c|c|c|c|c|c|c|c|c|c|c|}
\hline \multirow[t]{2}{*}{ Patient group } & \multirow[t]{2}{*}{ Formula } & \multirow[t]{2}{*}{ Time (h) } & \multirow[t]{2}{*}{$n$} & \multirow[t]{2}{*}{$r$} & \multicolumn{2}{|c|}{$\begin{array}{l}\text { Mean bias } \\
\text { (GFR1p - GFR7p) }\end{array}$} & \multicolumn{4}{|c|}{$\begin{array}{l}\text { Percentage of measures within } x \% \\
\text { of reference method }(\mathrm{P} x)^{\mathrm{a}}\end{array}$} & \multirow[t]{2}{*}{$P$ value } \\
\hline & & & & & Bias & Limits of agreement & P5 & $\mathrm{P} 10$ & P15 & P20 & \\
\hline \multirow{10}{*}{ CKD stages $4-5$} & GFR1p-Jacobsson & 5 & 23 & 0.90 & 2.1 & -7.0 to 11.3 & 43 & 70 & 96 & 96 & 0.03 \\
\hline & GFR1p-Jacobsson-mod. & 5 & 23 & 0.90 & 2.0 & -6.3 to 10.3 & 48 & 74 & 96 & 96 & 0.06 \\
\hline & GFR2p-JBM & 2 and 5 & 23 & 0.98 & -0.7 & -3.7 to 2.4 & 87 & 100 & 100 & 100 & 0.25 \\
\hline & GFR1p-Fleming & 3 & 18 & 0.83 & -2.0 & -11.7 to 7.6 & 22 & 39 & 50 & 56 & N/A \\
\hline & GFR1p-Ham\&Piepz & 2 & 18 & 0.75 & 14.0 & $5.3-22.8$ & 0 & 0 & 6 & 6 & 0.008 \\
\hline & GFR1p-Groth\&Aasted & 2 & 18 & 0.77 & 1.7 & -15.3 to 18.7 & 6 & 28 & 28 & 39 & 0.45 \\
\hline & GFR1p-Stake & 3 & 18 & 0.75 & 0.6 & -11.4 to 12.6 & 28 & 39 & 50 & 56 & 0.84 \\
\hline & GFR1p-Jacobsson & 5 & 18 & 0.73 & -3.4 & -14.7 to 7.8 & 39 & 44 & 56 & 67 & 0.75 \\
\hline & GFR1p-Jacobsson-mod. & 5 & 18 & 0.75 & -2.9 & -13.9 to 8.0 & 33 & 44 & 61 & 78 & 0.75 \\
\hline & GFR2p-JBM & 2 and $5 \mathrm{~h}$ & 18 & 1.00 & -0.3 & $1.2-1.0$ & 83 & 100 & 100 & 100 & $<0.001$ \\
\hline
\end{tabular}

Evaluation of bias and accuracy for blood sampling for various patient groups and time points after iohexol injection. GFR (mL/min/1.73m $\left.{ }^{2}\right)$ was determined by one-point methods and by the reference method (GFR7p). Mean bias, 95\% limits of agreement and correlation $(r)$ with reference method is shown calculated

GFR glomerular filtration rate; $C K D$ chronic kidney disease; $B S A$ body surface area

${ }^{a}$ Estimated accuracy is shown as P5, P10, P15 and P20, the percentage of patients within $\pm 5 \%, 10 \%, 15 \%$ and $20 \%$ of the reference. For comparison, the two-point method of Jødal Brøchner Mortensen (GFR2p-JBM) was added

${ }^{\mathrm{b}}$ Comparison with Fleming P10 at $3 \mathrm{~h}$

our iohexol study has shown that this formula gives an accurate mGFR determination in children with CKD 13.These findings are of great clinical value. For the follow-up of children with cancer treated with nephrotoxic substances, as well as for children with renal and urologic diseases and mild and moderate kidney dysfunction, it is clearly beneficial to reduce the number of blood draws from two to three to a single sample. The risk of outliers is an issue in all tests, and in a single-point procedure it is necessary to redo the test if a result is surprising, whereas using a multi-point GFR procedure it is possible to remove the outlier based on examination of the elimination curve.

A limitation of this study is the lack of inulin-based gold standard analyses, but the continuous intravenous infusion and timed urine collections necessary in inulin clearance is cumbersome, and inulin is nowadays difficult to obtain. In addition, the number of patients in our study was limited to 96 children, which reduces the power of subgroup analysis. The last time point of iohexol measurement at $5 \mathrm{~h}$ may limit the value of the study in patients with severely reduced kidney function. However, the validity of our study is strengthened by our comparisons of a high number of blood samples at different time points and with multiple formulas.

\section{Conclusion}

Determination of GFR in children at all ages with CKD stage 1-3 based on iohexol plasma clearance and single-point sampling at $3 \mathrm{~h}$ analyzed with the Fleming formula achieved the same level of performance as the two-point method. All other tested single-point formulas had a considerably lower performance. When the GFR is lower than $30 \mathrm{~mL} / \mathrm{min} / 1.73$ $\mathrm{m}^{2}$, a procedure with at least two blood-samples is recommended for mGFR.

Acknowledgements We are very grateful to the pediatric study nurses Hildur Grindheim and Renathe Håpoldøy at the Pediatric Clincial Trial Unit, Haukeland University Hospital and pediatric study nurse May Britt Lynum at the Pediatric Department, Oslo University Hospital for their high-quality assistance in collecting the data, and to laboratory engineer Kjersti Carstensen for the iohexol analyses.

The study was supported by grants from the Health Trust of Western Norway, Haukeland University Hospital, Oslo University Hospital, and The Norwegian Society of Nephrology.

\section{Compliance with ethical standards}

Financial disclosure The authors have no financial relationships relevant to this article to disclose.

Approval The study was approved by the Regional Ethics Committee of Western Norway and an informed consent form was signed by all patients and/or their designees. The study was performed in accordance with the Declaration of Helsinki.

Conflict of interests The authors declare that they have no conflict of interest.

Open Access This article is distributed under the terms of the Creative Commons Attribution 4.0 International License (http:// creativecommons.org/licenses/by/4.0/), which permits unrestricted use, 
distribution, and reproduction in any medium, provided you give appropriate credit to the original author(s) and the source, provide a link to the Creative Commons license, and indicate if changes were made.

\section{References}

1. Schwartz GJ, Munoz A, Schneider MF, Mak RH, Kaskel F, Warady BA, Furth SL (2009) New equations to estimate GFR in children with CKD. J Am Soc Nephrol 20:629-637

2. Krutzen E, Back SE, Nilsson-Ehle I, Nilsson-Ehle P (1984) Plasma clearance of a new contrast agent, iohexol: a method for the assessment of glomerular filtration rate. J Lab Clin Med 104:955-961

3. Schwartz GJ, Furth S, Cole SR, Warady B, Munoz A (2006) Glomerular filtration rate via plasma iohexol disappearance: pilot study for chronic kidney disease in children. Kidney Int 69:20702077

4. Schwartz GJ, Abraham AG, Furth SL, Warady BA, Munoz A (2010) Optimizing iohexol plasma disappearance curves to measure the glomerular filtration rate in children with chronic kidney disease. Kidney Int 77:65-71

5. Brown SC, O'Reilly PH (1991) Iohexol clearance for the determination of glomerular filtration rate in clinical practice: evidence for a new gold standard. J Urol 146:675-679

6. Gaspari F, Perico N, Ruggenenti P, Mosconi L, Amuchastegui CS, Guerini E, Daina E, Remuzzi G (1995) Plasma clearance of nonradioactive iohexol as a measure of glomerular filtration rate. J Am Soc Nephrol 6:257-263

7. Lindblad HG, Berg UB (1994) Comparative evaluation of iohexol and inulin clearance for glomerular filtration rate determinations. Acta Paediatr 83:418-422

8. Brøchner-Mortensen J (1972) A simple method for the determination of glomerular filtration rate. Scand J Clin Lab Invest 30:271274

9. Brøchner-Mortensen J, Haahr J, Christoffersen J (1974) A simple method for accurate assessment of the glomerular filtration rate in children. Scand J Clin Lab Invest 33:140-143

10. Fleming JS, Wilkinson J, Oliver RM, Ackery DM, Blake GM, Waller DG (1991) Comparison of radionuclide estimation of glomerular filtration rate using technetium $99 \mathrm{~m}$ diethylenetriaminepentaacetic acid and chromium 51 ethylenediaminetetraacetic acid. Eur J Nucl Med 18:391-395

11. Fleming JS, Zivanovic MA, Blake GM, Burniston M, Cosgriff PS (2004) Guidelines for the measurement of glomerular filtration rate using plasma sampling. Nucl Med Commun 25:759-769

12. Jacobsson L (1983) A method for the calculation of renal clearance based on a single plasma sample. Clin Physiol 3:297-305

13. Stake G, Monclair T (1991) A single plasma sample method for estimation of the glomerular filtration rate in infants and children using iohexol, I: establishment of a body weight-related formula for the distribution volume of iohexol. Scand J Clin Lab Invest 51:335342

14. Gaspari F, Guerini E, Perico N, Mosconi L, Ruggenenti P, Remuzzi G (1996) Glomerular filtration rate determined from a single plasma sample after intravenous iohexol injection: is it reliable? J Am Soc Nephrol 7:2689-2693

15. Fisher M, Veall N (1975) Glomerular filtration rate estimation based on a single blood sample. Br Med J 2:542

16. Groth S, Aasted M (1981) 51Cr-EDTA clearance determined by one plasma sample. Clin Physiol 1:417-425

17. Itoh K, Matsuyama T (2002) The single-plasma-sample method for determining the glomerular filtration rate with Tc-99m- diethylenetriamine pentaacetic acid in childhood and adolescence: is it age-dependent? Ann Nucl Med 16:541-548

18. Eriksen BO, Mathisen UD, Melsom T, Ingebretsen OC, Jenssen TG, Njølstad I, Solbu MD, Toft I (2010) Cystatin C is not a better estimator of GFR than plasma creatinine in the general population. Kidney Int 78:1305-1311

19. McMeekin H, Wickham F, Barnfield M, Burniston M (2016) A systematic review of single-sample glomerular filtration rate measurement techniques and demonstration of equal accuracy to slopeintercept methods. Nucl Med Commun 37:743-755

20. Groth S, Aasted M (1984) 51Cr-EDTA clearance determined by one plasma sample in children. Clin Physiol 4:75-83

21. Stake G, Monn E, Rootwelt K, Monclair T (1991) A single plasma sample method for estimation of the glomerular filtration rate in infants and children using iohexol, II: establishment of the optimal plasma sampling time and a comparison with the 99Tcm-DTPA method. Scand J Clin Lab Invest 51:343-348

22. Fleming JS, Persaud L, Zivanovic MA (2005) A general equation for estimating glomerular filtration rate from a single plasma sample. Nucl Med Commun 26:743-748

23. Tøndel C, Bolann B, Salvador CL, Brackman D, Bjerre A, Svarstad E, Brun A (2017) Iohexol plasma clearance in children: validation of multiple formulas and two-point sampling times. Pediatr Nephrol 32:311-320

24. Sapirstein LA, Vidt DG, Mandel MJ, Hanusek G (1955) Volumes of distribution and clearances of intravenously injected creatinine in the dog. Am J Phys 181:330-336

25. Haycock GB, Schwartz GJ, Wisotsky DH (1978) Geometric method for measuring body surface area: a height-weight formula validated in infants, children, and adults. J Pediatr 93:62-66

26. Ham HR, Piepsz A (1991) Estimation of glomerular filtration rate in infants and in children using a single-plasma sample method. J Nucl Med 32:1294-1297

27. Brown LD, Cai T, DasGupta A (2001) Interval estimation for a binomial proportion. Statist Sci 16:101-133

28. Jødal L, Brøchner-Mortensen J (2009) Reassessment of a classical single injection 51Cr-EDTA clearance method for determination of renal function in children and adults. Part I: analytically correct relationship between total and one-pool clearance. Scand J Clin Lab Invest 69:305-313

29. Brøchner-Mortensen J, Jødal L (2009) Reassessment of a classical single injection 51Cr-EDTA clearance method for determination of renal function in children and adults. Part II: empirically determined relationships between total and one-pool clearance. Scand J Clin Lab Invest 69:314-322

30. Core Team R (2017) R: a language and environment for statistical computing. R Foundation for Statistical Computing, Vienna. www. R-project.org

31. Delanaye P, Ebert N, Melsom T, Gaspari F, Mariat C, Cavalier E, Bjork J, Christensson A, Nyman U, Porrini E, Remuzzi G, Ruggenenti P, Schaeffner E, Soveri I, Sterner G, Eriksen BO, Back SE (2016) Iohexol plasma clearance for measuring glomerular filtration rate in clinical practice and research: a review. Part 1: how to measure glomerular filtration rate with iohexol? Clin Kidney J 9:682-699

32. Delanaye P, Melsom T, Ebert N, Back SE, Mariat C, Cavalier E, Bjork J, Christensson A, Nyman U, Porrini E, Remuzzi G, Ruggenenti P, Schaeffner E, Soveri I, Sterner G, Eriksen BO, Gaspari F (2016) Iohexol plasma clearance for measuring glomerular filtration rate in clinical practice and research: a review. Part 2: why to measure glomerular filtration rate with iohexol? Clin Kidney J 9:700-704 